\title{
Mídias SOCIAIS DIGITAIS, PARTICIPAÇÃo POLÍTICA E PROTESTOS ANTICORRUPÇÃO
}

\author{
Wilson José Ferreira de OLIVEIRA*
}

\begin{abstract}
RESUMO: A utilização de mídias sociais digitais como instrumento para o recrutamento e a participação em eventos de protesto tem sido considerada pela literatura internacional como um dos principais ingredientes da transformação nas condições e dinâmicas de participação política nos últimos anos. No Brasil, os "protestos de junho" em 2013 evidenciaram a intensificação do uso da internet e das redes sociais no recrutamento e mobilização política. Este artigo pretende demonstrar que, o uso de tais ferramentas nos protestos anticorrupção no Brasil, a partir da onda de protestos iniciada internacionalmente em 2011, expressou o enfrentamento a um sistema político que monopolizava e represava insatisfações e demandas por transformação. Ele se tornou aos poucos um dos principais veículos de aglutinação, manifestação e ação de organizações, grupos e lideranças liberais, conservadores e de direita em torno de uma agenda comum. Esta análise mostra a relevância da dimensão política para compreender o processo de utilização das mídias sociais digitais na dinâmica da participação política.
\end{abstract}

PALAVRAS-ChAVE: Mídias sociais digitais. Participação política. Protesto anticorrupção.

\section{Introdução}

Semelhante ao que ocorreu inicialmente com o surgimento e a propagação de outras tecnologias como o rádio e a televisão, a emergência e a intensificação do uso das novas Tecnologias da Comunicação e Informação (TICs), tem sido objeto

UFS - Universidade Federal de Sergipe - Programa de Pós-Graduação em Sociologia. São Cristóvão - SE - Brasil. 49035-190 - etnografia.politica@gmail.com. https://orcid.org/0000-0001-81058885. 
de acirrados e polarizados debates no tocante aos seus impactos sobre as condições e dinâmicas de participação e de ação política: de um lado, os que adotam uma postura de ceticismo e enfatizam os efeitos maléficos dessas novas ferramentas; de outro, os entusiastas que acreditam no potencial dessas novas tecnologias para o melhoramento da comunicação entre cidadãos e eleitos, para o aumento da acessibilidade à informação, transparência, qualidade de comunicação, participação política, etc. (DELLA PORTA, 2013; DEIBERT, 2019).

No âmbito internacional, os estudos e as discussões dos impactos das novas TICs sobre as concepções e as práticas políticas, sobre as condições e dinâmicas organizacionais de mobilização e participação política e até mesmo sobre as lógicas práticas da ação política, etc., constituem temas que já vêm sendo abordados há alguns anos. No caso europeu, as experiências do "Movimento 5 Estrelas" na Itália, do "Podemos" na Espanha e do "Partido Pirata" na Alemanha, entre outros, exemplificam o peso e os impactos da introdução de plataformas digitais sobre as dinâmicas de participação, de reunião e, até mesmo, de decisão no âmbito das próprias organizações partidárias (DESERIIS, 2019; GERBAUDO, 2019). Nos EUA foi, inicialmente, no âmbito das eleições presidenciais que se tem observado, desde os anos de 2000, o significativo papel da internet na dinâmica eleitoral. Todavia, foi nas eleições de 2008 e de 2016 que ela se tornou uma das variáveis principais do jogo e do sucesso eleitoral (CHADWICK, 2013; CECCOBELLI, 2018). No âmbito mais especificamente do ativismo, o Movimento por Justiça Global e os movimentos Occupy e Indignados, constituem os principais marcos da utilização da internet e das mídias sociais digitais nos processos de recrutamento, de organização e de mobilização para a defesa de causas públicas (KAVADA, 2015).

Deste modo, uma série muito extensa de trabalhos tem evidenciado, não apenas o peso da internet e das mídias sociais digitais sobre a política e as dinâmicas de participação em movimentos e defesa de causas, mas, principalmente, como elas coproduzem as formas de conceber a política e o ativismo, as dinâmicas de estruturação e de organização dos partidos, eleições e movimentos sociais, como também as lógicas práticas de adesão e participação na política e na defesa de causas. Neste sentido, somos desafiados a pensar a intensificação do uso da internet e das mídias sociais digitais na política e no ativismo não como um efeito das novas TICs sobre a sociedade e a política, mas em suas relações de coprodução das estruturas sociais, políticas e culturais onde estamos vivendo e imersos cotidianamente. Isso porque a plataformização da sociedade é um processo bem mais geral que envolve a implementação de plataformas online e de seus mecanismos nos mais variados setores e experiências sociais, coproduzindo as formas de conceber e de viver em sociedade como um todo, ao construir ambientes completamente personalizados de serviços, informações e pessoas em diferentes setores da vida social (DIJCK; POELL, WALL, 2018; POELL; NIEBORG; DIJCK, 2020; DEIBERT, 2019; 
CESARINO, 2020). Tal aspecto constitui um dos ingredientes principais de uma maior "personalização" das experiências sociais e políticas e das dinâmicas e formas organizacionais de ação coletiva, proporcionando uma maior disposição para substituir as condições e os requisitos de identificação e participação política e coletiva por "redes sociais personalizadas entre os seguidores" (BENNETT; SEGEBERG, 2012, p.748).

Essa intensificação da comunicação via plataformas e mídias sociais digitais tem como base, também, novas formas de interlocução entre os diversos tipos de mídias, desde as mais antigas até as mais recentes, configurando um sistema híbrido que transforma os espaços e os recursos de poder e as dinâmicas de comunicação política nas interações entre atores e organizações políticas, mídias e públicos (CHADWICK, 2013). Esse ambiente midiático e digital híbrido configura um sistema complexo de mensagens e uma nova gramática digital que facilita a emergência e a propagação de formas de percepção, de compreensão, de sentimentos, de valores, de comportamentos, de práticas, etc., e proporciona novas dinâmicas de articulação e de participação política em causas às mais diversas (MATTONI, 2017).

Tais aspectos estão na origem de uma série de investigações que tomam a plataformização como um dos ingredientes principais das modificações nas relações entre mídias sociais e política, nos processos de mediatização das campanhas políticas, nos status das Fake News na discussão e debate político, na personalização da comunicação política e no populismo digital (CAIANI; PARENTI, 2010; CAIANI; KRÖLL, 2014; TRERÉ; BARASSI, 2015; DESERIIS, 2017; CESARINO, 2019). No tocante às análises das transformações nas condições e processos de participação política, destacam-se os trabalhos que investigam como isto tem transformado as próprias dinâmicas organizacionais e os repertórios de ação dos movimentos sociais, os processos de enquadramento das causas e de construção identitária, as dinâmicas de recrutamento e engajamento, os usos das novas mídias sociais nas mobilizações e protestos públicos, o ativismo digital, etc., (EARL, 2010; KARPF, 2018; PAVAN; MAINARD, 2018; KAVADA, 2015).

No Brasil, foi a partir do ciclo de protestos de junho de 2013 que a intensificação dos usos da internet e das mídias sociais digitais tornou-se um dos temas centrais tanto nas agendas de investigação sobre política, ativismo e movimentos sociais nas ciências sociais, quanto nos debates, discussões e agendas da própria realidade política. Estreitamente vinculada a esta conjuntura política de maior utilização das plataformas digitais, a produção brasileira tem se caracterizado por certa dependência dessa conjuntura no que diz respeito às formulações dos problemas e objetos de investigação. Relacionado a isso observa-se que tanto nos estudos que analisam as relações entre TICs e movimentos sociais quanto nos que se concentram nas relações entre internet e política, há um grande acúmulo de trabalhos empíricos sobre aspectos os mais variados e um escasso diálogo e confrontação com e 
entre a produção teórica sobre o tema (SILVA et al., 2020; SAMPAIO et al., 2018; SAMPAIO; BRAGATTO; NICOLÁS, 2016). Essa situação tende a "produzir uma polifonia que pouco contribui para o diálogo entre as pesquisas, o acúmulo teórico e empírico e o desenvolvimento de análises comparativas" (SILVA et al., 2020, p.65).

Uma das razões disso, tal como já observado em outras áreas de investigação, está na intensa importação e mobilização de uma literatura internacional produzida nos EUA e, principalmente, na Europa, combinada com uma ausência de diálogo e confronto teórico, conceitual e empírico com a produção nacional (COSTA, 2010; OLIVEIRA, 2013; OLIVEIRA; PETRARCA, 2018). Decorrente disso, a literatura mobilizada caracteriza-se justamente pelo "alto nível de abstração" com o objetivo principal de "nomear e interpretar os objetos empíricos analisados", ao invés de promover sua problematização teórica e conceitual e o confronto com a realidade empírica em investigação. Dito de outro modo, as perspectivas e os conceitos mobilizados não são utilizados para "analisar e problematizar a realidade" e, sim, como "como gramáticas para enquadrá-la e interpretá-la" (SILVA et al., 2020, p.64).

Assim, grande parte dos conceitos identificados na literatura atuam mais como "gramáticas", a partir das quais se apreende a realidade, e menos como teorias explicativas que pretendem oferecer hipóteses causais sobre os fenômenos ou processos abordados. Além disso, está praticamente ausente na literatura a confrontação com teorias alternativas ou concorrentes, que tendem a ser simplesmente ignoradas. O que é problematizado aqui, então, não são as escolhas teóricas presentes na literatura analisada, mas sim a forma como se mobiliza a teoria na maior parte dessa literatura. (SILVA et al., 2020, p.64).

Uma das principais consequências disso é que tende-se a reproduzir não apenas autores e conceitos, mas também problemáticas e objetos de análise próprios das sociedades ocidentais (principalmente dos EUA e da Europa), negligenciando o debate teórico e as investigações sobre as condições, os processos, as concepções e as práticas que fundamentam a intensificação do uso de plataformas e mídias sociais digitais na política e nos movimentos sociais, com base nas características próprias do sistema político brasileiro. Por isso, no que pese a grande quantidade de investigações empíricas de nossa produção acadêmica sobre os usos políticos das mídias sociais digitais (SILVA et al., 2020; SAMPAIO et al., 2018; SAMPAIO; BRAGATTO; NICOLÁS, 2016), ainda são raros os estudos que evidenciem de forma mais sistemática em que medida as condições e as dinâmicas próprias de configuração do sistema político brasileiro constitui um dos aspectos pertinentes para a compreensão das concepções e gramáticas políticas nativas, dos princípios de organização e das lógicas práticas que fundamentam os processos de emergência e 
de intensificação dos usos das mídias sociais digitais nas dinâmicas de participação política.

Em consonância com esse tipo de preocupação e de desafio, o objetivo principal deste artigo é salientar a pertinência de se levar mais a sério as relações entre as características de um sistema político fundado na aliança e o processo de emergência e de difusão de plataformas e mídias sociais digitais nos processos de mobilização e participação política. Trata-se, em outros termos, de formular uma análise de meio termo, centrada na caracterização do sistema político e que fique entre as teorizações sobre a plataformização e as análises empíricas dos usos políticos das mídias sociais digitais. Nesse sentido, o argumento principal é que, no Brasil, o uso intenso das mídias sociais digitais nas mobilizações e protestos anticorrupção a partir do ciclo de protestos iniciado em 2011 expressou o enfrentamento a um sistema político que monopolizava e represava insatisfações e demandas por transformação, tornando-se, aos poucos, um dos principais veículos de aglutinação, de manifestação e de ação das organizações, grupos e lideranças liberais, conservadores e de direita em torno de uma agenda comum.

Para dar conta disso, demonstrarei num primeiro momento, que o colapso do sistema de alianças que tem como marco inicial a onda de protestos de 2013 resultou de uma crescente diversificação do sistema político, ao mesmo tempo em que provocou uma maior proliferação e fragmentação de organizações partidárias e acelerou certa instabilidade e crise política e institucional. Isso implicou a articulação de uma série de demandas relacionadas à própria dinâmica do sistema político brasileiro com uma onda global de protestos anticorrupção. Em um segundo momento, examino as relações entre os protestos anticorrupção e os usos das plataformas e mídias sociais digitais como espaço e recurso de aglutinação de organizações, grupos e lideranças liberais, conservadores e de direita em torno de uma agenda comum.

\section{A participação entre fragmentação, dispersão e coalizões}

As condições e as dinâmicas de participação política no Brasil passaram por significativas mudanças nos últimos anos, no que diz respeito aos mecanismos e padrões de participação na defesa de causas públicas, à emergência e ampliação de organizações e lideranças associativas, como também ao engajamento cívico no processo eleitoral, evidenciando novas formas de articulação entre Estado, movimentos sociais e as instituições políticas e eleitorais. Neste sentido, observa-se o surgimento de novas organizações para promover e sustentar os protestos e as mobilizações em defesa de causas públicas diversas, como também atores que passam a mobilizar recursos diferenciados que possibilitam a criação de novas 
formas de atuação nas dinâmicas organizacionais e nas práticas de defesa de tais causas. Tais mudanças resultaram, entre outros aspectos, numa crescente diversificação das gramáticas e concepções de política, dos princípios e dinâmicas de organização, assim como dos contextos e das lógicas de ação política postos em prática por diferentes atores sociais (OLIVEIRA, 2020).

Exemplifica isso o surgimento de grupos autonomistas, originários dos protestos de 2003 em Salvador-BA e de 2004 em Florianópolis-SC, que ficaram conhecidos respectivamente como Revolta do Buzu e Revolta da Catraca Livre (OLIVEIRA; SANTOS, 2017). Tendo como mote principal a reivindicação pelo transporte público e gratuito, eram originários da participação no Fórum Social Mundial que ocorria em Porto Alegre-RS desde 2003 e que mobilizou organizações e movimentos sociais bastante heterogêneos, tais como: grupos socialistas, coletivos anarquistas, movimentos gay e feminista, ecologistas, o movimento estudantil independente e grupos defensores de direitos humanos variados. Tinham como base a emergência de novas organizações de defesa dos estudantes e da ampliação das fissuras no âmbito das próprias organizações de representação e no interior das organizações e lideranças que apoiavam os governos do Partido dos Trabalhadores (PT) (OLIVEIRA; SANTOS, 2017; SILVA, 2018). Suas bandeiras e repertórios estavam centrados no apartidarismo, na independência e autonomia em relação aos partidos políticos e aos agentes do Estado, na recusa das organizações estudantis tradicionais frente a sua proximidade com os governos do PT, na rejeição de centralização pelas lideranças e autoridades do Estado e das hierarquias de gênero, em performances cênicas, vestuário preto, queima de catracas, etc. (MENDES, 2017; ALONSO; MISCHE, 2016).

Semelhante diversificação encontra-se nas redes de organizações e lideranças de movimentos, sindicatos e pequenos partidos de esquerda, cuja atuação tem origem nos protestos dos anos de 1980 e 1990, centradas na defesa de uma agenda redistributiva e de políticas públicas em contraponto à exploração capitalista, às desigualdades sociais e à exclusão de classe (ALONSO; MISCHE, 2017). Os governos do PT deram origem a um novo tipo de ativismo, na medida em que passaram a atuar na administração pública, na direção da formulação de políticas, como as relativas a questões étnicas, de gênero, educacionais e fundiárias, como também ganharam voz com a instituição de conselhos e instâncias participativas (ABERS, SERAFIM, TATAGIBA, 2014). Tendo à frente organizações como a Central Única dos Trabalhadores (CUT) e o Movimento dos Trabalhadores Sem Teto (MSTS), entre outros, manifestaram uma postura crítica ao governo da então presidente Dilma Rousseff através de grandes mobilizações por reformas populares: "reforma urbana, reforma tributária, democratização das comunicações, desmilitarização da polícia e reforma política via constituinte exclusiva" (ALONSO, 
2017, p.54). Seus repertórios envolviam o uso de bandeiras e faixas vermelhas, camisetas e bottons com símbolos dos movimentos ou dos partidos.

Por fim, as organizações e grupos conservadores, liberais e de direita cuja origem remonta ao início dos anos 2000, mas que foram fortemente impulsionados em 2005 pela ampla e onipresente cobertura de jornais, revistas impressas e televisivas, blogs, páginas e mídias digitais, etc., do escândalo do Mensalão que era apresentado como o maior escândalo de corrupção do país (ALONSO, 2019; RODRIGUES, 2018). Têm como base a articulação de redes de ativismo cívico, empresarial, religioso e militar, crescentemente insatisfeitos com programas e ações das administrações petistas e um intenso associativismo liberal, conservador e autoritário, com a participação e apoio de partidos de oposição ao PT e com a presença em eventos regulares internacionais como o Fórum da Liberdade e vínculos com organizações e grupos transnacionais antiglobalização e de extremadireita. Entre os anos de 2003 e 2015 proliferaram os protestos, as manifestações, as organizações, os movimentos, as marchas, as frentes, as campanhas, os atos, etc., que tinham como mote a defesa de pautas e agendas liberais, conservadoras e autoritárias como contraponto à administração do PT (TATAGIBA; TRINDADE; TEIXEIRA, 2015; ALONSO, 2019)

Tais transformações no âmbito dos mecanismos e padrões de participação na defesa de causas públicas e das organizações e lideranças associativas estiveram associadas a dinâmicas de engajamento cívico no processo eleitoral e, mais especificamente, à manutenção de um nível elevado de fragmentação partidária nos diferentes níveis de governo (federal, estadual e municipal). Quando se consideram os resultados dos últimos pleitos eleitorais no Brasil tal aspecto salta aos olhos (NICOLAU, 2017). Neste sentido, os dados das eleições mais recentes para prefeitos e vereadores evidenciam que a fragmentação partidária nas Câmaras Municipais se manteve praticamente a mesma com pequenas oscilações. No pleito eleitoral de 2020, observa-se que em algumas capitais "o número de partidos aproxima-se do total de vereadores": em oito (8) capitais a proporção de vereadores por partido é de dois (2) e em apenas uma ultrapassa três (3) vereadores por partido (MELO, 2020). Se na eleição de 2012, o número de partidos já era elevado e os resultados indicaram uma maior concentração em algumas aglomerações partidárias, como era o caso do Partido Movimento Democrático Brasileiro (PMDB) ${ }^{1}$, Partido da Social Democracia Brasileira (PSDB) e PT, no pleito de 2016, há uma grande modificação das principais aglomerações partidárias com maiorias nos principais municípios e capitais. Um dos principais aspectos que caracteriza essa mudança foi o declínio eleitoral do PT entre as aglomerações principais, saindo da posição de terceiro partido com mais prefeitos

\footnotetext{
1 Em convenção de 2017 o Partido Movimento Democrático Brasileiro (PMDB) escolheu adotar seu nome e sua sigla original Movimento Democrático Brasileiro (MDB).
} 
eleitos para a décima posição (NICOLAU, 2017; CASALECCHI, 2018). Em 2020, a atomização é mais intensa do que nos anos anteriores e mais acentuada do que no plano federal, de modo que mesmo que se observe a continuidade de algumas legendas nacionalmente relevantes, fica difícil falar em partidos eleitoralmente mais fortes no plano municipal, na medida em que mesmo estes enfrentam problemas que não parecem muito diferente daqueles que foram costumeiramente designadas como "nanicas" no Congresso (MELO, 2020).

No que diz respeito às eleições para o executivo, legislativo e senado federal a fragmentação do sistema partidário e a crescente dispersão do poder aparecem com maior evidência ainda. Como bem destaca Nicolau (2017), entre 2002 e 2014 nenhum partido obteve mais de $20 \%$ das cadeiras para a Câmara dos Deputados. Todavia, segundo ele, as eleições de 2014 bateu todos os recordes, não apenas ao apresentar a "maior dispersão do poder partidário da história brasileira", mas principalmente por se caracterizar como a "maior fragmentação partidária da história das democracias" (NICOLAU, 2017, p.90). Um dos principais resultados desse pleito eleitoral foi a redução da bancada dos três maiores partidos PT, PMDB e PSDB. Por outro lado, a criação de três novas legendas para o pleito eleitoral de 2014 e de mais três logo após a eleição, no ano de 2015, contribuiu para o aprofundamento da dispersão e, consequentemente, de uma maior dificuldade na constituição e na manutenção de uma base parlamentar de apoio às iniciativas e projetos do executivo federal, o que resultou em sucessivas crises até o impeachment da presidenta Dilma Rousseff (NICOLAU, 2017).

As eleições de 2018 evidenciam o impacto de algumas destas transformações sobre o sistema político e eleitoral, possibilitando uma melhor compreensão da crise política e de suas consequências sobre o funcionamento do sistema político. Em primeiro lugar, está o crescimento quantitativo do eleitorado, associado a uma grande ampliação da infraestrutura eleitoral disponível (RIBEIRO; BORBA, 2019). Neste pleito eleitoral encontramos um total de 146805548 eleitores, o que representa um acréscimo de 542496 quando comparado com os dados de 2016 e de 3.195.207 com os de 2014. Tal aumento está associado também a uma significativa ampliação das seções de votação que o eleitor tinha à sua disposição nos últimos pleitos. Assim se, em 2014 esse total era de 427724 e em 2016 passou para 473797 nas eleições de 2018 ele sobe para 479516 seções, o que representa um aumento de 5537 unidades em relação a 2016 e de 51.792 em relação à eleição de 2014 . Contrariando uma tendência de progressiva diminuição da abstenção eleitoral que estava em curso até as eleições de 2014, as eleições de 2018 vão no sentido contrário de uma continuidade do crescimento tal como teve início nas eleições municipais de 2016. Ao que tudo indica, tal tendência está fortemente associada a um crescente descontentamento e insatisfação do eleitorado em relação ao próprio sistema político e eleitoral (RIBEIRO; BORBA, 2019). 
Todavia, mais importante ainda são as relações entre o processo eleitoral de 2018 e a ampliação da fragmentação e dispersão de poder entre os partidos eleitos. Neste sentido, observa-se que a média de partidos com representação na Câmara dos Deputados atinge um total de 30 em 2018, percentual mais alto desde a redemocratização. Algo semelhante ocorre no âmbito dos governos estaduais, uma vez que aumentou para 13 o número de partidos que são representados com governadores eleitos. Tal crescimento do número de partidos esteve associado a uma maior dispersão do poder entre os partidos e a um crescimento do número de partidos com certa maioria na Câmara dos Deputados e no Senado Federal. Quanto a isso, observa-se que se em 2014 eram três partidos que controlavam em torno de $37 \%$ dos parlamentares federais, após as eleições de 2018 esse percentual cai para 23\%. Ao mesmo tempo, tal eleição se caracteriza por certa quebra da estabilidade das disputas eleitorais que ocorria desde as eleições posteriores ao impeachment do presidente Fernando Collor de Melo, tendo o PT e o PSDB como pólos centrais das disputas eleitorais. Deste modo, o Partido Social Liberal (PSL) que na eleição de 2014 elegeu apenas um deputado federal, nas eleições de 2018 liderou a disputa presidencial e se torna um dos partidos com maior bancada na Câmara dos Deputados, com 52 deputados eleitos, muito à frente do MDB e PSDB. Algo semelhante ocorreu no Senado, na medida em que 20 partidos elegeram senadores em 2018, enquanto na eleição de 2010, em que foram substituídos os dois terços, esse índice chegou a 15 (RIBEIRO; BORBA, 2020).

Sem dúvida, não se pode tomar as eleições de 2018 e 2020 nos diferentes níveis como sinal de ruptura ou uma novidade em relação à tendência de aumento da fragmentação e de dispersão do poder entre os partidos no Brasil. Pelo contrário, como se sabe, o aprofundamento da fragmentação política e da dispersão do poder tem se apresentado como uma das características principais do sistema político brasileiro pós redemocratização (NICOLAU, 2017; RIBEIRO; BORBA, 2019). Todavia, tal aspecto se combina com outra característica própria do sistema político brasileiro, que é a organização de "governos de coalizão" que tem como base a formação de "supermaiorias legislativas", ou dito em outros termos, de blocos multipartidários de apoio parlamentar ao governo (ABRANCHES, 1988; 2018; NOBRE, 2013a; NICOLAU, 2017). É justamente a combinação destes dois elementos, uma crescente fragmentação e dispersão do poder associada à dinâmica de organização de governos de coalizão suprapartidários para garantir o apoio às iniciativas do executivo no legislativo, que possibilita compreender tanto a estabilidade e até continuidade das disputas partidárias nos pleitos eleitorais pósredemocratização, quanto a instabilidade institucional e recorrentes crises políticas que o país tem atravessado nos últimos anos.

Quanto a isso, pode-se tomar as eleições de 2014 como um evento significativo de como estes elementos se associam de forma um tanto diferente do padrão que 
estava em prática até então. De um lado, um salto enorme em termos de fragmentação e de dispersão do poder em relação aos anos anteriores. De outro, a crescente dificuldade de organização de um governo de coalizão para apoio parlamentar ao executivo. Esse padrão de combinação de alta fragmentação com baixa coalizão, que continua também nas eleições de 2018 , não pode ser compreendida com base em fatores e variáveis apenas do processo eleitoral. Isso porque tal associação está estreitamente ligada a uma maior diversificação dos canais e das formas de participação no sistema político, às suas relações com as organizações e os protestos anticorrupção iniciados no ciclo de protesto de 2013 e seus desdobramentos sobre as instituições políticas e o processo eleitoral (OLIVEIRA, 2020).

\section{Sistema de alianças, protestos anticorrupção e mídias digitais}

A onda de protesto que teve início em 2013 constituiu um marco importante na articulação de uma série de demandas provenientes do próprio sistema político brasileiro com uma onda global de protestos anticorrupção que teve início em 2011 (DELLA PORTA, 2017). Ela pode ser tomada como uma espécie de catalisador das recentes mudanças tanto nas condições e processos de utilização da luta contra a corrupção como uma causa pública no Brasil, quanto nas dinâmicas de funcionamento do próprio sistema político.

A década de 1990 constitui um marco importante da emergência de um discurso contra a corrupção, fundado nas noções de "boa governança", de "desregulação, de "redução dos gastos estatais", de "privatização", "desregulamentação" e "liberalização" como os principais remédios para a "doença da corrupção" (DELLA PORTA, 2017, p.663). Uma série de organismos, instituições financeiras, agências e organizações transnacionais deram sustentação e difundiram tal discurso por meio de comissões, conferências, campanhas e tratados internacionais de combate a tal ameaça (DE SOUSA, HINDESS; LARMOUR, 2010; SAMPSON, 2010). Já a onda de protestos que surgiu em 2011 trouxe à tona um outro paradigma anticorrupção. Contrariamente à dominação do livre mercado, do neoliberalismo e da desregulamentação, correlatas às noções anteriores de boa governança, a crítica foi direcionada à corrupção da democracia produzida pelo próprio neoliberalismo em função do crescente conluio entre o poder das oligarquias, o mundo financeiro e dos negócios e os políticos (DELLA PORTA, 2017). Denunciando a corrupção das elites no poder, a imoralidade e corrupção do sistema, o monopólio dos políticos e homem de negócios gananciosos, etc., tais protestos apresentaram a corrupção como um exemplo flagrante de causa de desigualdade: nesta perspectiva, os altos níveis de enriquecimento dos 1\% em detrimento do sofrimento dos $99 \%$ são apresentados como sinais claros da corrupção, injustiça e imoralidade do sistema. Diante disso, 
exigem mais transparência, democracia e liberdade, através de políticas anticorrupção participativas e horizontais e da criação de mecanismos de controle pelos próprios cidadãos.

As chamadas "Jornadas de Junho" de 2013 constituem um marco na articulação deste novo paradigma anticorrupção com uma série de descontentamentos e insatisfações tanto dos próprios setores que apoiavam o então governo do PT, mas que queriam avançar nas reformas e na qualidade dos serviços públicos, quanto daqueles mais conservadores e autoritários que invocavam um retorno ao "nacionalismo", a agendas conservadoras e à "ética na política" e que clamavam pelo fim da "corrupção do PT" (ALONSO; MISCHE, 2016; MENDES, 2017; OLIVEIRA; SANTOS, 2017; RODRIGUES, 2018; TATAGIBA; GALVÃO, 2019; SILVA, 2018; OLIVEIRA, 2020). Por isso, tais protestos foram apoiados por um público diversificado e heterogêneo como torcidas organizadas, associações de moradores, jovens, idosos, famílias, etc. Muitos destes sem ativismo prévio, tinham como base o recrutamento via redes de amizade, trabalho e família, agora associadas a redes virtuais como Facebook, YouTube, Blogs, etc., alcançando uma grande repercussão na mídia impressa, televisiva e digital.

Muito mais do que simples descontentamentos e insatisfações de setores de sustentação ou de grupos de oposição ao então governo do PT, "Junho de 2013" expressa uma grande diversificação tanto das redes de organizações e de militantes que davam suporte ao então governo do PT quanto das que desde o início lhe fizeram oposição, tornando-se uma espécie de gatilho para alavancar uma série de contradições, de tensões, de descontentamentos e de demandas que há muito já estavam pressionando o sistema político (OLIVEIRA; SANTOS, 2017; TATAGIBA; GALVÃO, 2019). Trata-se, mais propriamente, de certo desencanto, inconformidade e descontentamento contra um sistema político que funcionava sob a base de esmagadoras maiorias suprapartidárias, para o qual não existia nem situação nem oposição, fechando todas as forças de transformação e os canais possíveis de representação, transformando-se numa massa homogênea, amorfa e indistinta, numa amálgama de interesses sempre presente no governo, qualquer que seja o governo, num universo no qual não há espaço para polarização de posições políticopartidárias, mas apenas acomodação amorfa de posições contrárias (NOBRE, 2013b).

Acrescente-se a isso, o fato de que o PT que foi um dos principais partidos que nasceu e se construiu como reação a esse tipo de lógica política e partidária, em 2013 já tinha se tornado establishment há muito tempo, realizado o pacto com o peemedebismo e alcançado, inclusive, mais sucesso que o seu antecessor na ampliação de uma coalizão de A a Z (NOBRE, 2013b). Tal situação produzia uma espécie de blindagem do próprio sistema político, na medida em que represava descontentamentos, reivindicações e as forças de transformação e os próprios canais 
de representação. De um lado, a manutenção e até mesmo ampliação dos espaços e formas de participação institucional de movimento sociais no governo e nas redes da burocracia estatal, ao dar acesso a postos no Estado e na elaboração e formulação de políticas públicas a um conjunto de organizações e lideranças vinculadas a movimentos sociais e defesas de causas diversificadas, produzindo o que a literatura nacional denominou de "ativismo institucional" (ABERS, SERAFIM, TATAGIBA, 2007; PEREIRA, 2018). De outro, a manutenção e mesmo ampliação da coalizão com partidos e lideranças heterogêneas, conservadoras, religiosas, etc., contrárias a uma série de pautas e agendas dos movimentos sociais e que agiam na base de um sistema de vetos a iniciativas e programas governamentais. Como salienta Pereira (2018), isso explica, por exemplo, como que em meio a uma maior abertura do PT às demandas do movimento e da causa LGBT, coalizões do partido com grupos e lideranças religiosas conduzem ao mesmo tempo a um fechamento das oportunidades políticas para o movimento. Longe de se restringir à causa LGBT, tal padrão de interação entre movimentos sociais e Estado se fez constante num conjunto de questões que estavam na pauta governamental naquele momento: política urbana, desenvolvimento agrário, meio ambiente, segurança pública, educacional, questões raciais, quilombolas, etc.

Deste modo, em um sistema político caracterizado muito mais pela necessidade de construção de amplas alianças do que pelo confronto político entre movimentos e grupos opostos, o desencanto e o descontentamento foram direcionados contra o sistema. É neste sentido, de uma rejeição do próprio sistema político como um todo, que se pode melhor compreender por que se tratava de uma revolta contra "tudo o que está á́". A própria intensificação do uso da internet e das redes sociais na mobilização e recrutamento para os eventos de protesto de 2013, pode ser mais bem compreendida quando se considera que tais ferramentas deram início, em certa medida, ao rompimento da blindagem do sistema político que funcionava sob a lógica do peemedebismo, represando descontentamentos, insatisfações e demandas por transformação. Por um lado, porque tais usos expressavam certo descontentamento com o monopólio da formação da opinião e vocalização de insatisfações pela mídia tradicional, de modo que a própria mídia foi alvo de constantes ataques e palavras de ordem nos protestos. E, de outro lado, porque criaram seus próprios canais de participação e de enfrentamento do sistema, mobilizando, recrutando e levando o desencanto, o descontentamento e as insatisfações para as ruas. (NOBRE, 2013b).

Os desdobramentos destas tensões entre um sistema político que represava as possibilidades de transformação, pela combinação de uma diversificação das organizações e lideranças e dos próprios canais de participação com a manutenção de um padrão de governabilidade que desde 1994 se caracterizava pela existência de um grande conjunto de partidos do conhecido "centrão" participando e ocupando postos dos governos em âmbito nacional, constitui um dos fatores que fizeram do combate 
à corrupção uma das causas que agregava grupos e interesses os mais diversos. Seus desdobramentos nas eleições de 2014, nas mobilizações pelo impeachment da presidenta Dilma Rousseff em 2016 e nas eleições de 2018 levaram ao colapso do sistema de alianças estabelecido pelo PT e promoveram o realinhamento das forças em torno de um novo centro político.

Sendo assim, deve-se levar em conta que o aumento progressivo da participação política eleitoral ocorreu concomitante a uma grande diversificação dos canais e das formas de participação no sistema político e seus desdobramentos, cuja tensão se manifestou de forma emblemática nos protestos de "Junho de 2013". De um lado, o surgimento e a difusão de diversas organizações, movimentos e mobilizações que expressavam uma série de desencantos, descontentamentos e insatisfações relacionados à própria dinâmica do sistema político brasileiro, traduzindo-se numa espécie de revolta contra a persistência de um sistema político que funcionava sob a base da amplas alianças (coalizões, blocos suprapartidários, etc.) e que acabou por fechar os canais possíveis de transformação e de representação. De outro lado, a conversão dessa revolta contra o sistema como um todo, contra sua imoralidade e opacidade, numa mobilização e luta contra a corrupção do PT e o sistema de alianças que o mantinha no poder, através da aliança das organizações e lideranças liberais, conservadoras e autoritárias com redes diversificadas de atores e instituições vinculadas à grande mídia, às instituições jurídicas, empresariais, religiosas e militares e ao próprio sistema político-partidário (TATAGIBA, TRINDADE, TEIXEIRA, 2015).

Disto resultou uma forte associação entre o combate à corrupção e o antipetismo, que emergiu com maior força em 2015 e se propagou nas eleições de 2018. Isto possibilitou articular em um discurso comum atores, perspectivas e demandas heterogêneas, tendo como traços principais o antipartidarismo, o antiesquerdismo, o antiestatismo, a rejeição da classe política, entre outros. Acrescente-se, ainda, que esse discurso antipetista e antissistema está também relacionado ao papel estruturador desempenhado pela Operação Lava Jato no surgimento e na aceleração da crise do próprio sistema político, tanto ao oferecer oportunidades de protestos e mobilizações anti-PT quanto ao fragilizar e provocar o rompimento do sistema de alianças vigente. Esse discurso antipetista e antissistema, fundado numa forte negação da própria atividade política institucional, num sentimento de ineficácia e corrupção das instituições políticas, numa grande descrença nas próprias instituições democráticas e numa tendência a ignorar as regras e a legitimidade do regime democrático, está em parte na base do aumento progressivo da abstenção eleitoral desde as eleições de 2016.

Todavia, um dos efeitos mais significativos desse discurso antipetista e antissistema pode ser observado quando se considera o próprio redesenho do jogo político-eleitoral. Isto se expressa de maneira clara na ruptura da estabilidade da disputa eleitoral que vinha marcando os processos eleitorais em torno de três principais 
agremiações partidárias (PT, PMDB, PSDB), que exerciam uma espécie de liderança para todos os postos nos três níveis federativos, assim como no declínio eleitoral de alguns partidos tradicionais e na emergência de novas organizações partidárias que se apresentaram, em alguma medida, como representantes desse discurso antipetista e antissistema. Como já foi observado no tópico anterior, um dos resultados mais diretos disso foi o aumento significativo da diversificação e dispersão partidária tanto no nível federal quanto no estadual, algo que já estava presente nas eleições municipais de 2016, mas que teve um forte acréscimo no pleito de 2018.

Essa redefinição do jogo político partidário e eleitoral, no sentido de uma maior diversificação e dispersão partidária, não é um resultado simples e direto da ampla difusão do discurso antipetista e antissistema, das constantes denúncias de corrupção pela Operação Lava Jato contra os partidos que compunham o sistema de alianças do PT ou, ainda, do crescimento e diversificação das organizações e grupos liberais, conservadores e autoritários e sua articulação com organizações político-eleitorais.

Ela contou também com uma ampla utilização da internet e das mídias sociais digitais como ferramenta, inicialmente, para mobilização e recrutamento para os eventos de protesto e, depois, como recurso principal das campanhas eleitorais (MENDES, 2017). Esse uso intensivo das mídias sociais digitais nas mobilizações e campanhas eleitorais segue uma tendência iniciada antes mesmo de 2013, quando grupos antipetistas começaram a se organizar, tendo como recursos principais fóruns de discussão, blogs, sites e comunidades na internet, aglutinando jornalistas, professores, lideranças e grupos que não encontram expressão nos canais institucionais nem representação na política oficial (ROCHA, 2011; SANTOS JR, 2016; ROCHA, 2018). Em 2013 esse uso se tornou mais difuso e generalizado contra o sistema como um todo, tornando-se, aos poucos, um dos principais veículos de aglutinação, de manifestação e de ação das organizações, grupos e lideranças. A partir de 2015, a utilização das mídias passou a se concentrar nos grupos contrários ao PT e ao governo de Dilma Rousseff, demonstrando uma grande capacidade de mobilizar uma quantidade significativa de pessoas para protestar contra governos do PT e da esquerda. Nas eleições de 2018, as mídias sociais digitais (Youtube, Facebook, Twitter, etc.) tornaram-se os principais canais de discussão e debate durante as campanhas eleitorais (EVANGELISTA; BRUNO, 2019; CESARINO, 2019; 2020).

Nas eleições de 2018 as mídias sociais digitais tiveram um papel crucial na campanha que deu origem à vitória de Jair Bolsonaro. Este e seus apoiadores desenvolveram uma estratégia de campanha centrada no uso de mídias sociais digitais: youtube, facebook, twitter e especialmente no uso do whatsapp (EVANGELISTA; BRUNO, 2019; CESARINO, 2019; CHAGAS, 2021). Tal investimento teve como base certas características próprias do whatsapp, na medida em que possibilita a 
atuação de grupos como uma "organização militar" (referida por eles como "exército virtual"), a segmentação destes grupos em tópicos específicos: kit gay, família, comunismo, armas, privatização, etc, como também favorece uma forte "relação de confiança", contribuindo para que a maioria dos conteúdos seja impulsionada por amigos e familiares (EVANGELISTA; BRUNO, 2019, p.17-18).

Um dos principais efeitos dessa estratégia de campanha foi que partidos com maior tempo de propaganda eleitoral televisiva na eleição de 2018 não se foram os mais bem sucedidos, tanto na eleição para presidente, deputados federais e senadores, quanto na para governadores e deputados estaduais, rompendo uma tendência do tempo de propaganda na TV como um dos recursos principais para o sucesso eleitoral, principalmente na disputa para o executivo federal. Desse modo, o uso intensivo das mídias sociais digitais contra o domínio das campanhas eleitorais pela televisão, contribuiu decisivamente para a redefinição do jogo político partidário. Isso porque diferentemente da recorrente concentração da disputa partidária em 3 principais partidos e polarizadas em dois principais, os quais eram justamente aqueles que detinham um tempo maior de propaganda eleitoral, assiste-se em 2018 a um redesenho do jogo político-partidário com a vitória eleitoral de novos partidos que tinham um tempo reduzido de propaganda, mas um uso intensivo das mídias sociais digitais. Tais resultados, muito mais do que ir na contramão da crescente fragmentação do sistema político, favorecem seu aumento e ampliação.

\section{Conclusões}

A intensificação dos usos das mídias sociais digitais na política e nos movimentos sociais se insere num processo mais geral de plataformização da sociedade e de crescente digitalização das experiências individuais em diversas facetas da vida social, desde aquelas mais públicas até as mais privadas e pessoais. Não se trata, portanto, de um simples efeito das novas TICs sobre a sociedade e a política e sim de relações de coprodução de estruturas sociais, políticas e culturais nas quais estamos imersos e vivendo cotidianamente. A implementação de plataformas online e de suas ferramentas digitais produz novas formas de conceber e de viver muitas das atividades que são tidas como próprias da política. Tais aspectos estão entre os ingredientes principais das modificações de uma série de relações e de atividades no âmbito da política: as formas de conceber a própria política e o ativismo; as dinâmicas de estruturação e de organização dos partidos; os processos de midiatização das campanhas eleitorais; as lógicas práticas de participação na defesa de causas; a personalização da comunicação política e o populismo digital, entre outras.

Certamente, esse processo de plataformização e midiatização das experiências sociais e políticas não constitui uma novidade própria da sociedade brasileira, nem 
tão pouco das características de nosso sistema político. Várias sociedades com características históricas, sociais, políticas e culturais muito distintas têm passado por dinâmicas semelhantes. Ao mesmo tempo, ainda que gerais tais processos não são automáticos nem se instalam nestas sociedades no mesmo período, da mesma forma e na mesma direção. Ao que tudo indica, essa variação ocorre porque há uma forte relação entre as características próprias do sistema político e os processos de emergência e de difusão das mídias sociais digitais, mesmo que ainda sejam poucos os trabalhos que se voltem mais sistematicamente para o exame de tal relação. Em consonância com isso, esse artigo procurou colocar no centro da análise as relações entre os processos de emergência e de intensificação dos usos das mídias sociais digitais na política e as condições e as dinâmicas próprias de configuração do sistema político brasileiro. De maneira mais específica, tratou-se de evidenciar a relevância de analisar as relações entre as características de um sistema político baseado nas alianças entre lideranças políticas de organizações heterogêneas e o processo de emergência e de difusão de plataformas e mídias sociais digitais nos processos de mobilização e participação política.

Como se pôde ver pelos dados referentes aos diferentes processos eleitorais, a fragmentação política, a dispersão do poder e a organização de governos de coalizão sustentados por blocos multipartidários de apoio parlamentar, constituem traços recorrentes da política brasileira. Paralelamente, à diversificação dos canais e das formas de participação no sistema político e seus desdobramentos sobre as instituições políticas e o processo eleitoral, crescia o desencanto, o descontentamento e as insatisfações contra a blindagem de um sistema fundado em amplas alianças. Deste modo, a maior propagação das mídias digitais como instrumento de mobilização política ocorre justamente num momento de grande descontentamento com o monopólio da formação da opinião e da vocalização de insatisfações pela mídia tradicional, decorrente de seus vínculos com as coalizões e alianças em diferentes governos. Por isso, grupos e organizações diversificadas criaram seus próprios canais de participação e de enfrentamento do sistema, mobilizando, recrutando e levando o desencanto, o descontentamento e as insatisfações para as ruas. É, portanto, num contexto político de grande rejeição do sistema político como um todo que há uma grande difusão das mídias sociais digitais como instrumento de mobilização política.

Neste sentido, a intensificação do uso da internet e das mídias sociais digitais nas mobilizações e protestos anticorrupção a partir do ciclo de protestos iniciado em 2011, pode ser mais bem compreendida quando se considera que tais ferramentas expressaram o enfrentamento a um sistema político que funcionava sob a lógica do peemedebismo, represando descontentamentos, insatisfações e demandas por transformação, tornando-se, aos poucos, um dos principais veículos de aglutinação, de manifestação e de ação das organizações, grupos e lideranças heterogêneas em torno de uma agenda comum. É tal aspecto que vai se tornar constante também na 
utilização das mídias sociais digitais na campanha de 2014, nos protestos contra o governo em 2015 e como estratégia de campanha eleitoral em 2018, constituindo-se, aos poucos, como um dos principais recursos para o sucesso eleitoral, principalmente na disputa para o executivo federal e contribuindo, decisivamente, para a vitória eleitoral de Jair Bolsonaro à Presidência da República e para a reconfiguração partidária no âmbito estadual e federal. Tal dinâmica de utilização das mídias digitais não se limitou ao processo eleitoral, transformando-se, ao invés disso, num dos principais ingredientes de comunicação política do novo presidente com seus apoiadores.

Tal aspecto é relevante, na medida em que sinaliza para certas continuidades e mudanças quanto às condições e dinâmicas da participação eleitoral e de suas relações com as organizações e os protestos anticorrupção, evidenciando o quanto as eleições de 2014 e de 2018 foram profundamente impactadas pelo contexto de forte ruptura e crise do sistema de alianças que estava na base de certa estabilidade e continuidade das disputas eleitorais. Essa forte relação com o contexto político permite uma compreensão mais sistemática de como a intensificação do uso das mídias sociais digitais têm impactado uma série de relações e de atividades no âmbito da política: desde as que dizem respeito às concepções da política e do ativismo, até as que remetem tanto às dinâmicas de estruturação e de funcionamento das organizações políticas e partidárias quanto às lógicas práticas de participação em atividades e grupos políticos.

Desta forma, a análise aqui apresentada evidencia uma série de continuidades e rupturas do sistema político que precisam ser melhor aprofundados e caracterizados para dar conta de como as condições e dinâmicas de utilização das mídias sociais digitais nos processos políticos e nas formas de mobilização e participação na defesa de causas, podem estar relacionados a fenômenos tão gerais como a personalização da comunicação política e o populismo digital, que se tornaram, nos últimos anos, um dos ingredientes principais da política brasileira. Tal proposta analítica difere de grande parte da literatura brasileira sobre TICs, política e movimentos sociais, que tende a privilegiar a importação e mobilização de perspectivas e conceitos de alto nível de abstração como gramáticas para enquadrar e interpretar a realidade, ao invés de promover sua problematização teórica e conceitual com base no confronto com a realidade empírica em investigação. Em contraponto a isso, este artigo procurou formular uma análise de meio termo, centrada na caracterização do sistema político brasileiro e que se mantém entre as teorizações mais gerais sobre a plataformização e digitalização das experiências sociais e políticas e a análise empírica de como a recente intensificação dos usos políticos das mídias sociais digitais no Brasil estão relacionados a certos traços de configuração e funcionamento do próprio sistema político brasileiro que de longa data tem como base o sistema de alianças entre organizações e lideranças heterogêneas. 


\title{
DIGITAL SOCIAL MEDIA, POLITICAL PARTICIPATION AND ANTI-CORRUPTION PROTESTS
}

\begin{abstract}
The use of digital social media as instrument for recruiting and participating in protest events has been considered by international literature like the main ingredient of the transformation in the conditions and dynamics of political participation in recent years. In Brazil, the "June protests" in 2013 highlighted the intensification of the use of internet and social media in political mobilization and recruitment. This article intends to demonstrate that the use of such tools in the anti-corruption protests in Brazil, from the wave of protest demonstrations starting internationally in 2011, expressed the confrontation with a political system which monopolized and avoided dissatisfactions and demands for transformation. They gradually became one of the main vehicles for the "liberal", "conservative" and "right-wing" organizations, groups and leaders around a common agenda. This analysis highlights the relevance of the "political dimension" to understand the process of using digital social media in the dynamics of political participation.
\end{abstract}

KEYWORDS: Digital social media. Political participation. Anti-corruption protests.

\section{MEDIOS SOCIALES DIGITALES, PARTICIPACIÓN POLÍTICA Y PROTESTAS ANTICORRUPCIÓN}

\begin{abstract}
RESUMEN: El uso de los medios sociales digitales como herramienta de captación y participación en actos de protesta ha sido considerado por la literatura internacional como uno de los principales ingredientes de la transformación de las condiciones y dinámicas de participación política en los últimos años. En Brasil, las "protestas de junio" de 2013 destacaron la intensificación del uso de Internet y los medios sociales en la captación y movilización política. Este artículo pretende demostrar que el uso de dichas herramientas en las protestas anticorrupción en Brasil, a partir de la ola de protestas que se iniciaron a nivel internacional en 2011, expresó la confrontación con un sistema político que monopolizaba y reprimía el descontento y las demandas de transformación. Poco a poco se convirtieron en uno de los principales vehículos de aglutinación, manifestación y acción de organizaciones, grupos y liderazgos "liberales", "conservadores" y "de derechas" en torno a una agenda común. Este análisis muestra la relevancia de la "dimensión política" para entender el proceso de uso de los medios sociales digitales en la dinámica de la participación política.
\end{abstract}

PALABRAS CLAVE: Medios sociales digitales. Participación política. Protesta anticorrupción. 


\section{REFERÊNCIAS}

ABERS, Rebecca; SERAFIM, Lizandra; TATAGIBA, Luciana. Repertórios de interação estado-sociedade em um estado heterogêneo: a experiência na Era Lula. Dados, v. 57, n. 2, p.325-357, 2014.

ABRANCHES, S. H. Presidencialismo de coalizão: raízes e evolução do modelo político brasileiro. São Paulo: Companhia das Letras, 2018.

ABRANCHES, S. H. Presidencialismo de coalizão: o dilema institucional brasileiro. Dados, v. 31, n. 1, p.5-33, 1988.

ALONSO, Angela. A gênese de 2013: formação do campo patriota. Journal of Democracy em Português, v. 8, p.30, 2019.

ALONSO, Angela. A política das ruas: protestos em São Paulo de Dilma a Temer. Novos Estudos - CEBRAP, v. 37, n. 1, p.49-58, 2017.

ALONSO, Angela; MISCHE, Ann. Changing Repertoires and Partisan Ambivalence in the New Brazilian Protests: June 2013 in Brazil. Bulletin of Latin American Research, v. 36, n. 2, p.144-159, 2016. Disponível em: https://doi.org/10.1111/blar.12470. Acesso em: 24 mar. 2021.

BENNETT, W. Lance; SEGERBERG, Alexandra. The Logic of Connective Action: Digital media and the personalization of contentious politics. Information, Communication \& Society, [S. 1.], v. 15, n. 5, p.739-768, 2012. Disponível em: https://doi.org/10.1080/13691 18X.2012.670661. Acesso em: 24 mar. 2021.

CAIANI, Manuela; KRÖLL, Patricia. The transnationalization of the extreme right and the use of the Internet. International Journal of Comparative and Applied Criminal Justice, [S. l.], v. 39, n. 4, p.331-351, 2014. Disponível em: https://doi.org/10.1080/01924036.201 4.973050. Acesso em: 24 mar. 2021.

CAIANI, Manuela; PARENTI, Linda. The Dark Side of the Web: Italian Right-Wing Extremist Groups and the Internet. South European Society and Politics, [S. 1.], v. 14, n. 3, p.273-294, 2010. Disponível em: https://doi.org/10.1080/13608740903342491. Acesso em: 24 mar. 2021.

CASALECCHI, Gabriel Ávila. Julian. Participação Política. Brasil em Números, v. 26, p.189-200, 2018.

CECCOBELLI, Diego. Not every day is Election Day: a comparative analysis of eighteen election campaigns on Facebook. Journal of Information Technology \& Politics, [S. 1.], v. 15, n. 2, p.122-141, 2018. Disponível em: https://doi.org/10.1080/19331681.2018.1449 701. Acesso em: 24 mar. 2021. 
CESARINO, L. Como vencer uma eleição sem sair de casa. Internet\&sociedade, v. 1, n. 1, p.91-120, 2020.

CESARINO, L. Identidade e representação no bolsonarismo. Revista de Antropologia, v. 62, n. 3, p.530-557, 19 dez. 2019.

CHADWICK, Andrew. The hybrid media system: politics and power. Oxford ; New York: Oxford University Press, 2013. (Oxford studies in digital politics). E-book. Introdução e caps.: $1,2,4$ e 9 .

CHAGAS, Viktor. Meu malvado favorito: os memes bolsonaristas de WhatsApp e os acontecimentos políticos no Brasil. Revista Estudos Históricos, v. 34, n. 72, p.169-196, 2021.

COSTA, S. Teoria por Adição. In: MARTINS, C. B.; MARTINS, H. H. T. de S.; BOTELHO, A. (Eds.). Horizontes das ciências sociais no Brasil. Sociologia. São Paulo-SP: ANPOCS : Instituto Ciência Hoje : Discurso Editorial : Barcarolla, 2010. p.25-51.

DE SOUSA, L.; HINDESS, B.; LARMOUR, P. Governments, Ngos and Anti-corruption The New Integrity Warriors. [s.1.] Routledge, 2010.

DEIBERT, Ronald J. Três duras verdades sobre as redes sociais. Journal of Democracy em Português, [S. 1.], v. 8, 1, p.27-50, 2019.

DELLA PORTA, Donatella. Anti-Corruption from Below. Social Movements Against Corruption in Late Neoliberalism. Partecipazione e Conflitto, 3. [S.1: s.n.]. 2017. Disponível em: https://doi.org/10.1285/i20356609v10i3p661. Acesso em: 23 mar. 2021.

DELLA PORTA, Donatella. Can democracy be saved? participation, deliberation and social movements. Cambridge Malden, MA: Polity, 2013.

DESERIIS, Marco. Digital movement parties: a comparative analysis of the technopolitical cultures and the participation platforms of the Movimento 5 Stelle and the Piratenpartei. Information, Communication \& Society, [S. 1.], p.1-17, 2019. Disponível em: https://doi. org/10.1080/1369118X.2019.1631375. Acesso em: 23 mar. 2021.

DESERIIS, Marco. Technopopulism: The Emergence of a Discursive Formation. tripleC: Communication, Capitalism \& Critique. Journal for a Global Sustainable Information Society, [S. 1.], v. 15, n. 2, p.441-458, 2017. Disponível em: https://doi.org/10.31269/triplec. v15i2.770. Acesso em: 23 mar. 2021.

DIJCK, José van; POELL, Thomas; WAAL, Martijn de. The platform society. New York: Oxford University Press, 2018. 
EARL, Jennifer et al. Changing the world one webpage at a time: conceptualizing and explaining internet activism. Mobilization: An International Journal, [S. 1.], v.15, 4, p.425-446, 2010.

EVANGELISTA, Rafael; BRUNO, Fernanda. WhatsApp and political instability in Brazil: targeted messages and political radicalisation. Internet Policy Review, 2019. Disponível em: https://policyreview.info/articles/analysis/whatsapp-and-political-instability-brazil-targetedmessages-and-political. Acesso em: 23 mar. 2021.

GERBAUDO, Paolo. The digital party: political organisation and online democracy. London: Pluto Press, 2019.

KARPF, David. Analytic Activism and Its Limitations. Social Media + Society, [S. 1.], v. 4, n. 1, 2018. Disponível em: https://journals.sagepub.com/doi/full/10.1177/2056305117750718. Acesso em: 23 mar. 2021.

KAVADA, Anastasia. Creating the collective: social media, the Occupy Movement and its constitution as a collective actor. Information, Communication \& Society, [S. 1.], v. 18, n. 8, p.872-886, 2015. Disponível em: https://doi.org/10.1080/1369118X.2015.1043318. Acesso em: 24 mar. 2021.

MATTONI, A. A situated understanding of digital technologies in social movements. Media ecology and media practice approaches. Social Movement Studies, v. 16, n. 4, p.494-505, 4 jul. 2017.

MELO, C. R. Por que a fragmentação não diminuiu nas capitais? UOL - Observatório das Eleições. Publicado em 25 de novembro de 2020. Disponível em: https://noticias.uol.com. br/colunas/observatorio-das-eleicoes/2020/11/25/por-que-a-fragmentacao-nao-diminuiu-nascapitais.htm. Acesso em: 29 nov. 2020.

MENDES, Mariana S. Brazil's Popular Awakening - June 2013. Accounting for the onset of a new cycle of contention. In: DELLA PORTA, Donatella (org.). Global diffusion of protest: riding the protest wave in the neoliberal crisis. Protest and social movements. Amsterdam: Amsterdam University Press, 2017. p.59-84.

NICOLAU, J. M. Os Quatro Fundamentos da Competição Política no Brasil (1994-2014). Journal of Democracy em Português, 1. v. 6, p.32, 2017.

NOBRE, Marcos. Imobilismo em movimento: da abertura democrática ao governo Dilma. São Paulo: Companhia das Letras, 2013a.

NOBRE, Marcos. Choque de democracia: Razões da revolta. São Paulo: Companhia das Letras, 2013b. 
OLIVEIRA, Wilson José Ferreira de. Anti-corruption protests, alliance system and political polarization. Civitas - Revista de Ciências Sociais, v. 20, n. 3, p.439-453, 2020. (A luta contra a corrupção: estado da arte e perspectivas de análise).

OLIVEIRA, Wilson José Ferreira de. A Arte de Resistir às Palavras: inserção social, engajamento político e militância múltipla. In: SEIDL, Ernesto; GRILL, Igor Gastal. (org.). As Ciências Sociais e o Espaço da Política no Brasil. Rio de Janeiro: FGV, 2013, p.141178 .

OLIVEIRA, Wilson José F. de e PETRARCA, Fernanda Rios. "Inovações Temáticas, 'Guinadas' Teóricas e Tradição Intelectual no Brasil”. Revista Brasileira de Sociologia RBS 6, $n^{\circ}$ 14, p.34-62, 2018.

OLIVEIRA, Wilson José F. de; SANTOS, Adrielma Silveira F. dos. Eventos de protesto, repertórios organizacionais e dinâmicas de construção do transporte público e gratuito como uma causa pública. Dilemas-Revista de Estudos de Conflito e Controle Social, v. 10, n. 3, p.599-620, 2017.

PAVAN, Elena; MAINARDI, Arianna. Striking, Marching, Tweeting. Studying How Online Networks Change Together with Movements. PArtecipazione e COnflitto - The Open Journal of Sociopolitical Studies: 2, 2018. Disponível em: https://oi.org/10.1285/ i20356609v11i2p394. Acesso em: 24 mar. 2021.

PEREIRA, Matheus Mazzilli. Oportunidades Políticas em um Presidencialismo de Coalizão. Lua Nova: Revista de Cultura e Política, no 105, p. 217-52, 2018.

POELL, T.; NIEBORG, D.; DIJCK, J. V. Plataformização. Fronteiras - estudos midiáticos, v. 22 , n. 1, p.2-10, 4 abr. 2020.

RIBEIRO, Ednaldo; BORBA, Julian. Participação Política. Brasil em Números, v. 27, p.189-206, 2019.

RIBEIRO, Ednaldo; BORBA, Julian. Participação Política. Brasil em Números, v. 28, p.189-206, 2020.

ROCHA, Camila. O boom das novas direitas brasileiras: financiamento ou militância? In: SOLANO, Esther; ROCHA, Camila (orgs.). O ódio como política: a reinvenção das direitas no Brasil. Coleção Tinta vermelha. 1 ed. São Paulo: Boitempo, 2018. v. 1. p.15-20.

ROCHA, Maria Eduarda da Mota. Em busca de um ponto cego: notas sobre a sociologia da cultura no Brasil e a diluição da mídia como objeto sociológico. Sociedade e Estado, v. 26, n. 3, p.453-470, 2011.

RODRIGUES, Lidiane Soares. Uma revolução conservadora dos intelectuais (Brasil/2002-2016). Política \& Sociedade, v. 17, n. 39, p.277-312, 2018. 
SAMPAIO, R. C.; BRAGATTO, R. C.; NICOLÁS, M. A. A construção do campo de internet e política: análise dos artigos brasileiros apresentados entre 2000 e 2014. Revista Brasileira de Ciência Política, n. 21, p.285-320, dez. 2016.

SAMPAIO, R.; MitOZO, I.; MASSUChIN, M.; FONTES, G.; PENTEAdO, C. Ciberpolítica, ciberativismo e cibercultura: uma análise dos papers apresentados no grupo de trabalho da Anpocs. Revista Brasileira de Informação Bibliográfica em Ciências Sociais, n. 85 , p.126-147, 7 ago. 2018.

SAMPSON, S. The anti-corruption industry: from movement to institution. Global Crime, v. 11, n. 2, p.261-278, 28 abr. 2010.

SANTOS JR, Marcelo Alves Dos. Vai Pra Cuba!!! A rede antipetista na eleição de 2014. 197 p. Dissertação de Mestrado. Universidade Federal Fluminense, Niterói, 2016.

SILVA, M. K. A apropriação conservadora do ciclo de protestos de 2013: rumo aos protestos anti-Dilma? Lusotopie, v. 17, n. 1, p.88-111, 10 set. 2018.

SILVA, M. K.; PEREIRA, M. M.; FERNANDES, E. G.; RUSKOWSKI, B.; SILVA, C. F. da. Tecnologias de Informação e Comunicação, Ativismo e Movimentos Sociais: uma revisão crítica da literatura brasileira (2010-2017) na perspectiva do campo de estudos de movimentos sociais. Compolitica, v. 10, n. 2, p.43-77, set. 2020.

TATAGIBA, Luciana; GALVÃO, Andreia. Os protestos no Brasil em tempos de crise (2011-2016). Opinião Pública, v. 25, n. 1, p.63-96, 2019. Disponível em: https://doi. org/10.1590/1807-0191201925163. Acesso em: 24 mar. 2021.

TATAGIBA, Luciana; TRINDADE, Thiago; TEIXEIRA, Ana Cláudia Chaves. Protestos à direita no Brasil (2007-2015). In: CRUZ, Sebastião Velasco; KAYSEL, André; CODAS, Gustavo (orgs.). Direita, volver! o retorno da direita e o ciclo político brasileiro. 1. ed. São Paulo: Fundação Perseu Abramo, 2015. p.197-212.

TRERÉ, Emiliano; BARASSI, Veronica. Net-authoritarianism? How web ideologies reinforce political hierarchies in the Italian 5 Star Movement. Journal of Italian Cinema \& Media Studies, [S.1.], v. 3, n. 3, p.287-304, 2015. Disponível em: https://doi.org/10.1386/ jicms.3.3.287_1. Acesso em: 24 mar. 2021.

Recebido em 15/02/2021.

Aprovado em 08/04/2021. 